\title{
O EMBASAMENTO ARQUEANO E PALEOPROTEROZÓICO DO ORÓGENO ARAÇUAÍ
}

\author{
Carlos M. Noce ${ }^{1}$; Antônio Carlos Pedrosa-Soares ${ }^{1}$; \\ Luiz Carlos da Silva ${ }^{2}$ \& Fernando F. de Alkmim ${ }^{3}$
}

Resumo

\begin{abstract}
O embasamento do Orógeno Araçuaí compreende essencialmente os complexos Guanhães, Gouveia, Porteirinha, Mantiqueira e Juiz de Fora. Os quatros primeiros possuem caráter autóctone a para-autóctone e representam o embasamento cratônico retrabalhado no domínio orogênico. O Complexo Juiz de Fora está tectonicamente justaposto ao Complexo Mantiqueira por meio de extensa zona de cisalhamento neoproterozóica, a Falha de Abre Campo. Os complexos Guanhães, Gouveia e Porteirinha assemelham-se ao arcabouço arqueano do Quadrilátero Ferrífero, incluindo gnaisses e migmatitos TTG (tonalito-trondhjemito-granodiorito, plutons graníticos e seqüências do tipo greenstone belt. As idades conhecidas de eventos e unidades geológicas, entretanto, não são perfeitamente correlatas àquelas do Quadrilátero Ferrífero. No Complexo Guanhães os gnaisses/migmatitos TTG foram datados entre 2867 e $2711 \mathrm{Ma}$, e um corpo granítico em 2710 Ma. No Complexo Gouveia ocorre uma sequência greenstone belt de 2971 Ma, e uma intrusão granítica foi datada em 2839 Ma. Datações U-Pb não estão disponíveis para o Complexo Porteirinha.

O Complexo Mantiqueira é composto predominantemente por ortognaisses bandados, cuja cristalização magmática ocorreu no intervalo 2180-2041 Ma. Os dados isotópicos de Sr e Nd sugerem uma origem por processos de fusão de crosta continental antiga. Já os ortognaisses granulíticos do Complexo Juiz de Fora possuem assinatura isotópica dominantemente juvenil e cristalizaram entre 2134 e $2084 \mathrm{Ma}$. A associação de rochas do Complexo Mantiqueira corresponde a arco(s) magmático(s) desenvolvido(s) sobre a margem do paleocontinente arqueano, enquanto o Complexo Juiz de Fora parece representar um arco intra-oceânico. Estes complexos constituem segmentos de um orógeno riaciano, desenvolvido entre 2,2 e 2,05 Ga, e retrabalhado pela Orogenia Brasiliana.
\end{abstract}

\begin{abstract}
Basement units of the Araçuaí Orogen are the Guanhães, Gouveia, Porteirinha, Mantiqueira, and Juiz de Fora complexes. The first four units are autochthonous to parautochthonous, and are considered to be the reworked margin of the São Francisco Craton, now located in the Araçuaí Orogen. The Juiz de Fora complex is juxtaposed against the Mantiqueira complex by a dextral-reverse, high-angle shear zone of Brasiliano age (the Abre Campo Fault). The Archean basement of the Quadrilátero Ferrífero region can be traced into the Guanhães, Gouveia, and Porteirinha complexes, which display TTG gneisses and migmatites, granite plutons and greenstone belt sequences. However, ages of geologic units and events are not exactly the same as in the Quadrilátero Ferrífero. TTG gneisses within the Guanhães Complex yielded magmatic ages between 2867 and $2711 \mathrm{Ma}$, and a granite pluton was dated at $2710 \mathrm{Ma}$. A greenstone belt sequence and a granite pluton of the Gouveia Complex were dated at $2971 \mathrm{Ma}$ and $2839 \mathrm{Ma}$, respectively. U-Pb ages are not available for the Porteirinha Complex.

The Mantiqueira complex consists predominantly of banded biotite-amphibole orthogneiss, with magmatic ages at 2180-2041 Ma. Sr and Nd signatures suggest that the gneiss protholits were essentially generated by partial melting of crustal material. On the other hand, granulite facies orthogneisses of the Juiz de Fora Complex make up calc-alkaline suites of juvenile affinity, and crystallized at 2134-2084 Ma. The Mantiqueira Complex is a magmatic arc built up along the Archean margin of the São Francisco Paleocontinent, whilst the Juiz de Fora Complex probably evolved within an oceanic magmatic arc setting, or on a very stretched continental crust. They are envisaged as segments of a Rhyacian orogen that evolved at 2.2-2.05 Ga, latter reworked by he Brasiliano Orogeny.
\end{abstract}

\section{INTRODUÇÃO}

O embasamento do Orógeno Araçuaí evoluiu a partir da aglutinação de blocos crustais arqueanos durante um processo orogênico paleoproterozóico que estendeu-se, aproximadamente, entre 2,2 e 2,0 Ga. Neste evento ocorreu a consolidação do bloco continental São Fancisco-Congo que, provavelmente, fazia parte de um extenso continente Paleoproterozóico (e.g. Atlântica Paleocontinent, Rogers \& Santosh 2004). Os núcleos antigos, arqueanos, dos blocos São Francisco e Congo foram amalgamados ao longo de um cinturão orogênico denominado Itabuna-SalvadorCuraçá no Brasil (Barbosa \& Sabaté 2004), e Eburneano na África (Ledru et al. 1994). Esta ponte cratônica foi poupada dos eventos orogênicos neoproterozóicos e sobreviveu até o Mesozóico (Porada 1989; Ledru et al. 1994; Trompette 1994; Brito-Neves et al. 1999; Barbosa \& Sabaté 2004; Alkmim et al. 2006).

No domínio do Orógeno Araçuaí, e da sua contraparte africana representada pelo Orógeno Congo Ocidental, o sistema orogênico paleoproterozóico, com seus núcleos arqueanos, foi profundamente retrabalhado e desmembrado, constituindo hoje as unidades do embasamento orogênico. No Orógeno Araçuaí estas unidades de embasamento encontram-se expostas no domínio externo (oeste) e interno (leste) do orógeno. O domínio externo compreende o cinturão de dobra- 
mento-cavalgamento, de baixo grau metamórfico, que bordeja o Craton do São Francisco. No domínio interno estão expostos os volumosos corpos granitóides relacionados às diversas etapas evolutivas do orógeno, $\mathrm{o}$ metamorfismo atinge o fácies granulito e ocorre extensa anatexia. Este posicionamento em setores distintos do orógeno faz com que seja variável a intensidade do retrabalhamento tectônico e isotópico dos complexos do embasamento, durante a Orogênese Brasiliana.

Diversos complexos majoritariamente constituídos por ortognaisses formam o embasamento do Orógeno Araçuaí. Estes são os complexos Guanhães, Gouveia, Porteirinha, Mantiqueira e Juiz de Fora (Figura 1). O Complexo Guanhães é parte do núcleo arqueano
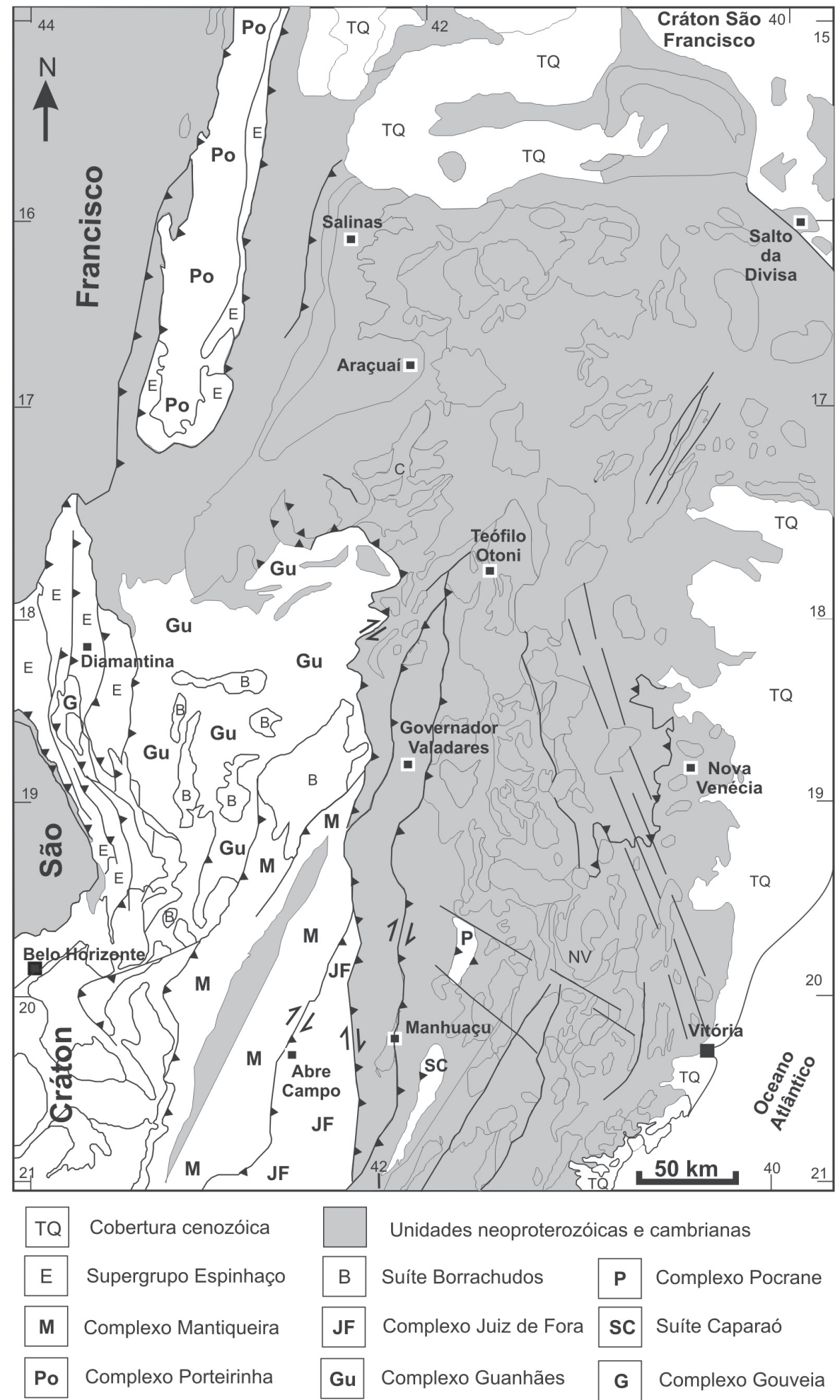

Figura 1: Mapa geológico do Orógeno Araçuaí, destacando as unidades do embasamento (modificado de Pedrosa-Soares et al. 2001) 
do embasamento do Cráton do São Francisco Meridional, núcleo este que era bordejado por um orógeno marginal paleoproterozóico (o Cinturão Mineiro de Teixeira 1985; ver também a reconstituição geotectônica proposta por Alkmim \& Marshak 1998). O Orógeno Araçuaí intercepta o limite Arqueano-Paleoproterozóico original, de forma que o Complexo Guanhães (Arqueano) e o Complexo Mantiqueira (Paleoproterozóico) podem ser vistos como unidades de caráter autóctone a paraautóctone que representam o embasamento cratônico retrabalhado no domínio orogênico. O Complexo Mantiqueira, portanto, é entendido como um segmento retrabalhado, no domínio Araçuaí, do Cinturão Mineiro. Os complexos Gouveia e Porteirinha representam exposições, em janelas estruturais/erosivas, de associações rochosas predominantemente arqueanas e são interpretados à maneira do Complexo Guanhães. O Complexo Juiz de Fora possui caráter alóctone, encontrando-se tectonicamente justaposto ao Complexo Mantiqueira por meio de extensa zona de cisalhamento neoproterozóica, a Falha de Abre Campo.

\section{GEOLOGIA, IDADE E EVOLUÇÃO DOS COMPLEXOS DO EMBASAMENTO}

\section{Complexos Guanhães, Gouveia e Porteirinha.}

O embasamento do setor meridional do Cráton do São Francisco encontra-se bem representado na região do Quadrilátero Ferrífero, onde o Supergupo Minas (2,5-2,2 Ga) assenta-se sobre terrenos arqueanos constituídos por domos gnáissico-migmatíticos de composição TTG (tonalito-trondhjemito-granodirito) com idades $\geq 2,9 \mathrm{Ga}$, plutons granitóides neoarqueanos e pelo Greenstone Belt Rio das Velhas (2790-2750 Ma; vide Machado et al. 1992, Noce et al. 1998, Noce et al. 2005). As características deste arcabouço arqueano do Quadrilátero Ferrífero repetem-se nos complexos Guanhães e Gouveia (Figura 1), embora as idades de eventos e unidades geológicas não sejam perfeitamente correlatas. No Complexo Guanhães ocorrem gnaisses e migmatitos TTG datados entre 2867 e $2711 \mathrm{Ma}$ (Figura 2E), corpos graníticos, um dos quais datado em $2710 \mathrm{Ma}$ (Silva et al. 2002), faixas metavulcanosedimentares possivelmente arqueanas e seqüências metassedimentares portadoras de formações ferríferas bandadas (correlacionáveis às do Supergrupo Minas). O complexo aloja os corpos graníticos da Suíte Borrachudos (1740 \pm 8 a 1670 $\pm 32 \mathrm{Ma}$; Silva et al. 2002, Chemale Jr. et al. 1997), relacionada à abertura do rifte Espinhaço.

O Complexo Gouveia ocorre no núcleo de estrutura antiformal do Supergrupo Espinhaço, onde estão expostas rochas gnáissico-migmatíticas, um granito datado em ca. 2839 Ma e uma sequência greenstone belt de ca. 2971 Ma (Machado et al. 1989).

O Complexo Porteirinha ocupa posição semelhante à do Complexo Gouveia, na zona mais externa do orógeno, mas já próximo de seu limite setentrional
(Figura 1). É composto por gnaisses bandados com composição predominantemente granodiorítica, localmente migmatizados, que contêm intercalações concordantes de anfibolitos e de rochas metaultramáficas (serpentinito, clorita xisto e actinolita xisto). Os gnaisses bandados/migmatitos são injetados por plutons de composição granodiorítica, granítica e sienítica, estes últimos exibindo texturas magmáticas bem preservadas. Ocorre também sequência metavulcano-sedimentar constituída por xistos aluminosos, xistos quartzofeldspáticos, anfibolitos e metaultramáficas (Roque et al. 1993). Datações U-Pb não estão disponíveis para este complexo. Entretanto, em sua provável extensão setentrional, no Estado da Bahia, uma associação de gnaisses, migmatitos e granulitos denominada Complexo Santa Izabel forneceu idades arqueanas muito antigas, da ordem de $3350 \mathrm{Ma}$ (Rosa et al. 2000). Na mesma região um extenso batólito sienítico, provavelmente correlacionável aos corpos de mesma composição encontrados no Complexo Porteirinha, foram datados em ca. $2050 \mathrm{Ma}$ (Rosa et al. 2000).

\section{COMPLEXO MANTIQUEIRA}

Ao sul do Quadrilátero Ferrífero, na borda cratônica, ocorre uma associação de corpos máficos e granitóides de composição tonalítica a granítica, datados entre 2220 e $2050 \mathrm{Ma}$ (Noce et al. 1998, 2000, Valença et al. 2000, Ávila 2000, Silva et al. 2002, Teixeira et al. 2004). O Complexo Mantiqueira representa a continuação desta associação plutônica no domínio do Orógeno Araçuaí (Figura 1).

O Complexo Mantiqueira tem sido englobado em mais de uma unidade litoestratigráfica desde a definição original da Série Mantiqueira por Barbosa (1954). Desta forma, em função do autor, a mesma associação litológica pode ser parcial ou totalmente incluída no Gnaisse ou Complexo Piedade (Ebert 1958, Machado Filho et al. 1983, Silva et al. 2002), no Complexo Gnáissico-Migmatítico (Silva 1978) ou no Complexo Barbacena (Hasui \& Oliveira 1984). A designação Complexo Mantiqueira deve-se a Brandalise (1991). Uma síntese atual sobre a evolução dos conhecimentos sobre esta unidade pode ser encontrada em Heilbron et al. (2003).

O litotipo predominante é um biotita-anfibólio ortognaisse bandado de composição tonalítica a granítica. Lentes, boudins e camadas concordantes de anfibolito são freqüentes (Figuras 2B e 2C). A alternância de bandas félsicas e máficas, com espessura centimétrica a decimétrica, é uma característica marcante das rochas do Complexo Mantiqueira (Figuras 2A e 2F). Estruturas migmatíticas tipo schlieren, dobrada e surreítica são comuns. O bandamento dos gnaisses Mantiqueira parece derivar tanto de processos de migmatização como da intensa deformação experimentada por estas rochas, responsável pelo estiramento de corpos magmáticos distintos e sua disposição em camadas paralelas. Embora o bandamento/foliação exibido 

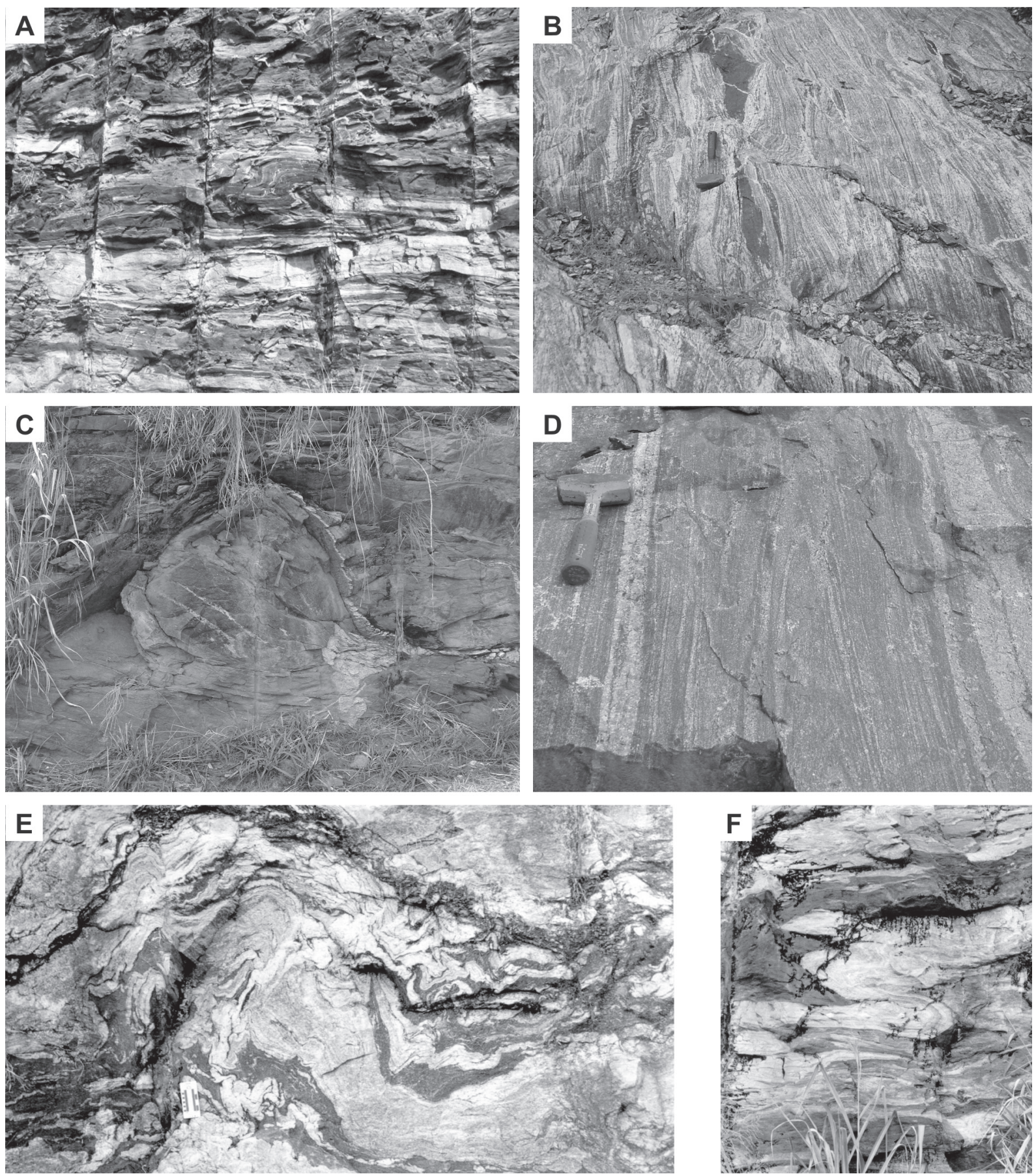

Figura 2: Imagens de afloramento de gnaisses do embasamento do Orógeno Araçuaí. A e F: bandamento característico dos gnaisses Mantiqueira; B e C: encraves anfibolíticos nos gnaisses Mantiqueira;

D: Gnaisse enderbítico do Complexo Juiz de Fora com bandas mais claras (leucossoma) de composição charnockitica; E: Gnaisse bandado TTG, arqueano, do Complexo Guanhães.

pelos gnaisses, tipicamente de baixo ângulo e orientado entre N-S e NNE-SSW, seja uma estrutura atribuível à tectônica brasiliana (vide Peres et al. 2004), em algumas exposições é possível constatar que esta resulta do intenso dobramento e transposição de uma estrutura bandada mais antiga.

Os ortognaisses constituem suítes cálcio-alcalinas, enquanto as rochas máficas representam basaltos do tipo transicional (Duarte et al. 2004). Remanescentes de rochas supracrustais no Complexo Mantiqueira são bastante subordinados, principalmente representados por xenólitos de rochas cálcio-silicáticas e quartzito (Figueiredo \& Teixeira 1996).

Idades U-Pb SHIMP para a cristalização magmática dos gnaisses Mantiqueira variam entre 2180 e 2041 Ma (Silva et al 2002, Noce et al. 2007). As assinaturas isotópicas de $\mathrm{Sr}$ e $\mathrm{Nd}$, e a abundância de zircões herdados nas amostras datadas, indicam que os protólitos foram dominantemente gerados por fusão parcial de material crustal arqueano, e o ambiente geotectônico mais provável seria o de arco magmático continental (Figueiredo \& Teixeira 1996, Fischel et 
al. 1998, Duarte et al. 2004, Noce et al. 2007). Uma análise dos dados U-Pb sugere que o magmatismo de arco estendeu-se até ca. $2100 \mathrm{Ma}$, seguido por estágios colisionais a pós-colisionais até ca. $2050 \mathrm{Ma}$, aos quais se associa um primeiro evento metamórfico onde temperaturas expressivas foram alcançadas (Silva et al. 2002, 2005, Noce et al. 2007).

\section{Complexo Juiz de Fora}

O termo Complexo Juiz de Fora refere-se originalmente à extensa faixa de rochas granulíticas com direção NE-SW, que aflora na região limítrofe entre os estados de Minas Gerais e Rio de Janeiro, inicialmente estudada por Ebert $(1955,1957)$ e Rosier (1957). Várias propostas de definição, interpretação e subdivisão para esta associação litológica, muitas vezes conflitantes, foram apresentadas nas últimas décadas. Sugere-se a leitura da síntese de Heilbron et al. (2003), que apresenta uma análise dessas diversas contribuições sobre o Complexo Juiz de Fora e completa listagem bibliográfica. Segundo a definição de Heilbron (1993, 1995), o Complexo Juiz de Fora é constituído por ortognaisses e metabasitos com paragêneses da fácies granulito, que localmente mostram efeitos de evento metamórfico retrógrado, com formação de hornblenda e biotita a partir de piroxênios. As intercalações metassedimentares, incluídas no complexo por outros autores, foram interpretadas como escamas tectônicas da cobertura neoproterozóica. A partir destas premissas, e da idade de cristalização de $c a .2134 \mathrm{Ma}(\mathrm{U}-\mathrm{Pb})$ obtida por Machado et al. (1996) para uma rocha charnockítica do Complexo Juiz de Fora da região de Conservatória (RJ), pode-se caracterizar esta unidade como uma associação magmática de idade Transamazônica.

Em resumo, o Complexo Juiz de Fora é composto por ortognaisses com paragêneses da fácies granulito, e o litotipo característico é um gnaisse enderbítico (Figura 2D), granulação média, verde escuro, com bandamento centimétrico e intercalações máficas. Sua mineralogia essencial é plagioclásio, quartzo, ortopiroxênio e clinopiroxênio; biotita e hornblenda são produtos de reações retrometamórficas. Gnaisses de composição charnockítica são menos freqüentes, mas nos gnaisses enderbíticos é comum a presença de bandas e/ou injeções charnockíticas de cor mais clara e granulação mais grossa. Granulitos básicos ocorrem como bandas, lentes e/ou boudins, de tamanho centimétrico a métrico, encaixados nos gnaisses enderbíticos.

Os granulitos básicos, que localmente podem formar corpos mais expressivos, possuem granulação fina a média e estrutura maciça a fracamente foliada. A mineralogia primária é representada por ortopiroxê nio+clinopiroxênio e plagioclásio. Granada esqueletal em equilíbrio com o piroxênio é observada em algumas lâminas. Minerais secundários são biotita, anfibólio e quartzo. Estas rochas foram interpretadas por Costa (1998) como gabro-noritos, representando corpos intrusivos e/ou lavas básicas cristalizados em condições de fácies granulito, e cujo caráter toleiítico de baixo Ké similar a basaltos de arco-de ilha ou fundo oceânico.

Os gnaisses enderbíticos e charnockíticos constituem suítes cálcio-alcalinas de afinidade juvenil (Figueiredo \& Teixeira 1996, Duarte et al. 1997, Fischel et al. 1998). Idades U-Pb disponíveis para estes gnaisses, e para uma rocha máfica de composição gabro-diorítica, caem no intervalo 2134-2084 Ma (Machado et al. 1996, Heilbron et al. 2001, Noce et al. 2007). Segundo Duarte (1998) e Duarte \& Heilbron (1999), o primeiro evento metamórfico a afetar as rochas do complexo, responsável pela formação de paragêneses diagnósticas da fácies granulito (ortopiroxênio + plagioclásio \pm clinopiroxênio \pm hornblenda) em arranjo granoblástico, é anterior à formação da foliação regional, relacionada à Orogênese Brasiliana. A paragênese mineral associada a esta foliação tem caráter retrógrado, evidenciado pela cristalização de hornblenda, biotita e granada a partir de ortopiroxênio e clinopiroxênio. Datações U-Pb SHRIMP de Noce et al (2007) confirmam a hipótese de que estas rochas foram submetidos a metamorfismo de alto grau aproximadamente contemporâneo à cristalização magmática, ou seja, de idade paleoproterozóica.

\section{Suíte Caparaó e Complexo Pocrane}

As duas unidades de embasamento mais orientais do Orógeno Araçuaí são a Suíte Caparaó e o Complexo Pocrane, que orientam-se aproximadamente segundo o mesmo meridiano (Figura 1). O termo Suíte Caparaó refere-se a uma associação de granulitos de composição enderbítica, charnockítica, quartzo diorítica, diorítica e gabróica, que ocorre no núcleo de uma grande estrutura antiformal na serra homônima. Existem controvérsias a cerca da natureza destas rochas, que segundo alguns autores seriam derivadas de um protólito supracrustal (e.g. Söllner et al. 1991, Seidensticker \& Wiedemann 1992). Outros autores, entretanto, suportam uma natureza ortoderivada e consideram os granulitos como parte do Complexo Juiz de Fora (Campos Neto \& Figueiredo 1990). A origem ígnea de pelo menos parte dos litotipos da Serra do Caparaó é reforçada pelo estudo das características dos zircões de um gnaisse charnockítico cuja idade de cristalização magmática é $2195 \pm 15 \mathrm{Ma}$ (Silva et al., 2002, 2004). Esta idade é consideravelmente mais antiga que aquelas disponíveis para o Complexo Juiz de Fora (2134-2084 Ma), de forma que a correlação entre as duas unidades ainda é uma questão em aberto.

O Complexo Pocrane foi descrito como uma unidade constituída por biotita-hornblenda gnaisse, com ou sem granada, e exibindo abundantes lentes de anfibolito, rochas metassedimentares e rochas metaultramáficas (vide Tuller 2000). Sua idade é atribuída ao Arqueano/ Paleoproterozóico, embora as idades $\mathrm{Rb}$-Sr disponíveis apenas indiquem a re-homogenização isotópica total ou parcial durante a Orogênese Brasiliana (Silva 
et al 1987, Padilha 1993). Investigações de campo sugerem que a maior parte da área atribuída ao Complexo Pocrane representa, de fato, uma seqüência supracrustal associada à evolução do Orógeno Araçuaí, ainda que fragmentos do embasamento estejam também presentes. Isto é indicado pela idade de $1560 \pm 14 \mathrm{Ma}$ obtida em um corpo de anfibolito concordante em gnaisse bandado (Silva et al. 2002).

\section{CONSIDERAÇÕES FINAIS}

O embasamento do Orógeno Araçuaí inclui segmentos de idade predominantemente arqueana (complexos Guanhães e Gouveia) e paleoproterozóica (complexos Mantiqueira e Juiz de Fora). A associação de rochas dos complexos Mantiqueira e Juiz de Fora, os dados geoquímicos e isotópicos, bem como sua distribuição geográfica de oeste para leste, permitem sugerir que estas unidades representam, respectivamente, um arco magmático desenvolvido sobre a margem do paleocontinente arqueano, e um ou mais arcos magmáticos acrescionários (Figueiredo \& Teixeira 1996, Alkmin \& Marshak 1998, Heilbron et al. 2003, Duarte et al 2005, Noce et al. 2007, etc.). A superposição orogênica brasiliana dificulta a definição da compartimentação geotectônica anterior. Existe a sugestão da presença de descontinuidades relacionadas ao episódio acrescionário paleoproterozóico, como parece ser o caso da descontinuidade de Abre Campo, que separa terrenos com idades TDM arqueanas a oeste, associados ao Complexo Mantiqueira, dos terrenos paleoproterozóicos a leste representados pelo Complexo Juiz de Fora (Fischel et al. 1998). Já no Complexo Guanhães os terrenos arqueanos formados por gnaisses TTG e granitóides foram cavalgados pelas supracrustais neoproterozóicas dos grupos Rio Doce e Macaúbas, contendo possíveis restos ofiolíticos que marcam a sutura brasiliana. Ambas as descontinuidades têm orientação meridiana e podem praticamente se superpor.

\section{AGRADECIMENTOS}

Os autores agradecem ao CNPq pelo contínuo apoio às suas atividades científicas.

\section{REFERÊNCIAS BIBLIOGRÁFICAS}

Alkmim F.F., Marshak S., 1998. The Transamazonian orogeny in the Quadrilátero Ferrífero, Minas Gerais, Brazil: Paleoproterozoic collision and collapse in the Souhtern São Francisco Craton region. Precambrian Res., 90: 29-58.

Alkmim F.F., Marshak S., Pedrosa-Soares A.C., Peres G.G., Cruz S.C.P., Whittington A., 2006. Kinematic evolution of the AraçuaíWest Congo orogen in Brazil and Africa: Nutcracker tectonics during the Neoproterozoic assembly of West Gondwana. Precambrian Res., 149: 43-64.

Ávila C.A. 2000. Geologia, petrografia e geocronologia de corpos plutônicos paleoproterozóicos da borda meridional do Cráton do São Francisco, região de São João del Rei, MG. Tese de Doutorado, Instituto de Geociências, Universidade Federal do Rio de Janeiro, $401 \mathrm{p}$.
Barbosa J.S.F. \& Sabaté P. 2004. Archean and Paleoproterozoic crust of the São Francisco Craton, Bahia, Brazil: geodynamic features. Precambrian Res., 133:1-27.

Barbosa O. 1954. Evolution du geossinclinal Espinhaço. In: Inter Geol. Congr., Comptes. Rendus, section XIII, 19e session: 1-37, 1952, Argélia.hh

Brandalise L.A. 1991. Folha Barbacena, SF. 23-X-C-III, 1:100.000, Estado de Minas Gerais. (Programa Levantamentos Geológicos Básicos). Brasília, DNPM/CPRM. 162 p. (Texto explicativo).

Brito Neves B.B., Campos Neto M.C., Fuck R. 1999. From Rodinia to Western Gondwana: an approach to the Brasiliano-Pan African cycle and orogenic collage. Episodes, 22:155-199.

Campos Neto M.C. \& Figueiredo M.C.H. 1990. Evolução geológica dos terrenos Costeiro, Paraíba do Sul e Juiz de Fora (RJ-MG-ES). In: SBG, Congr. Bras. Geol., 36, Anais, 6:2631-2648.

Chemale Jr. F., Quade H., Van Schmus W.R.V. 1997. Petrography, Geochemistry and Geochronology of the Borrachudo Granite, Minas Gerais, Brazil. Zentralblatt fur Geologie und Paläontologie, 3-6: 739-750.

Costa A.G. 1998. The granulite-facies rocks of the northern segment of the Ribeira Belt, eastern Minas Gerais, SE Brazil. Gondwana Res., 1:367-372.

Duarte B. P., Figueiredo M.C.H., Campos Neto M., Heilbron M. 1997. Geochemistry of the Granulite Fácies Orthogneisses of Juiz de Fora Complex, Central Segment of Ribeira Belt, Southeastern Brazil. Rev. Brás. Geoc., 27: 67-82.

Duarte B. P. \& Heilbron M. 1999. Metamorphic Evolution of the Early to Medium Proterozoic Granulite Fácies Rocks of the Central Segment of the Brasiliano-Panafrican Ribeira Belt, Southeastern Brazil. In: European Union of Geociences, Strasbourg, France, Journal of Conference Abstracts, Cambridge Publications, 4:792.

Duarte B.P., Valente S.C., Heilbron M., Campos Neto M.C. 2004. Petrogenesis of the orthogneisses of the Mantiqueira Complex, Central Ribeira Belt, SE Brazil: An Archaean to Paleoproterozoic basement unit reworked during the Pan-African Orogeny. Gondwana Res, 7: 437-450

Duarte B.P., Heilbron M., Ragatky D., Valente S.C., 2005. Mantiqueira and Juiz de Fora Complexes: reworked basement units within a Western Gondwana mobile belt in Brazil. In: Academia Nacional de Ciências, Gondwana, 12, Abstracts, p. 142.

Ebert H. 1955. Pesquisas geológicas na parte sudeste do Estado de Minas Gerais. Rio de Janeiro, DGM, p. 79-89 (Relatório Anual do Diretor).

Ebert H. 1957. A Tectônica do sul do Estado de Minas Gerais e regiões adjacentes. Rio de Janeiro, DNPM/DGM, p. 97-107. (Relatório Anual do Diretor).

Ebert H. 1958. Discordâncias Pré-Cambrianas em Carandai, Minas Gerais: Rio de Janeiro, DNPM/DGM, Boletim 183, 48 p.

Figueiredo M.C.H. \& Teixeira W., 1996. The Mantiqueira Metamorphic Complex, eastern Minas Gerais State: preliminary geochronological and geochemical results. Anais Acad. Bras. Ciênc., 68:223-246.

Fischel D.P., Pimentel M.M., Fuck R.A., Costa A.G., Rosière, C.A 1998. Geology and Sm-Nd isotopic data for the Mantiqueira and Juiz de Fora Complexes (Ribeira Belt) in the Abre campo Manhaçu region, Minas gerais, Brazil. In: International Conference on Basement Tectonics, 14, Abstracts, p. 21-23.

Hasui Y. \& Oliveira M.A.F. 1984. A Província Mantiqueira: Setor Central. In: F.F.M. de Almeida \& H. Hasui (eds.). $O$ Precambriano do Brasil, São Paulo, Edgard Blucher, 344 p

Heilbron M. 1993. Evolução tectono-metamórfica da Seção Bom Jardim de Minas (MG) - Barra do Pirai (RJ). Setor Central da Faixa Ribeira. Tese de Doutoramento, Instituto de Geociências, Universidade de São Paulo, 268 p.

Heilbron M. 1995. O Segmento Central da Faixa Ribeira: Compartimentação Tectônica e Ensaio Evolutivo. Tese de Livre Docência, Universidade Estadual do Rio de Janeiro, 115p.

Heilbron M., Machado N., Duarte B. P. 2001. Evolution of the Paleoproterozoic Transamazonian Orogen in SE Brazil: a view from the Neoproterozoic Ribeira Belt. In: GAC-MAC Joint Annual Meeting, St. Johns, Canada, Abstracts, v.26, p.61.

Heilbron M., Duarte B., Valladares C., Nogueira J.R., Tupinambá M., Eirado L.G. 2003. Síntese geológica do bloco oriental (Zona 
da Mata). In: A.C. Pedrosa-Soares, C.M. Noce, R. Trouw, M Heilbron (coords.). Projeto Sul de Minas - Etapa I: Geologia e Recursos Minerais do Sudeste Mineiro. COMIG/UFMG/UFRJ/ UERJ, Belo Horizonte, v.1, p.8-50.

Ledru P., Johan V., Milési J.P., Tegyey M., 1994. Markers of the last stages of the Palaeoproterozoic collision: evidence for a $2 \mathrm{Ga}$ continent involving circum-South Atlantic provinces. Precambrian Res., 69:169-191.

Machado Filho L., Ribeiro M., Gonzalez S.R., Schenini C.A., Santos Neto A. dos; Palmeira R. C., Pires J.L., Teixeira W., Castro H.E.F 1983. Geologia das Folhas Rio de Janeiro (SF 23/24) escala 1:1.000.000, mapa e texto explicativo. Rio de Janeiro, MME. 780p. (Projeto RADAM Brasil).

Machado N., Schrank A., Abreu F.R., Knauer L.G., Almeida-Abreu P.A. 1989. Resultados preliminares da geocronologia $\mathrm{U} / \mathrm{Pb}$ na Serra do Espinhaço Meridional. In: SBG, Simp. Geol. MG., 5, Anais, p. 1-4.

Machado N., Noce C.M., Ladeira E.A., Belo de Oliveira O.A. 1992. $\mathrm{U}-\mathrm{Pb}$ geochronology of Archean magmatism and Proterozoic metamorphism in the Quadrilátero Ferrífero, southern São Francisco Craton, Brazil. Geol. Soc. Am. Bul., 104:1221-1227.

Machado N., Valladares C., Heilbron M., Valeriano C. 1996. U$\mathrm{Pb}$ geochronology of the central Ribeira belt (Brazil) and implications for the evolution of the Brazilian Orogeny. Precambrian Res., 69:347-361.

Noce C.M., Machado N., Teixeira W. 1998. U-Pb geochronology of gneisses and granitoids in the Quadrilátero Ferrífero (southern São Francisco craton): age constraints for Archean and Paleoproterozoic magmatism and metamorphism. Rev.Bras. Geoc., 28:95-102.

Noce C.M., Teixeira W., Quéméneur J.J.G., Martins V.T.S., Bolzachini, E. 2000. Isotopic signatures of Paleoproterozoic granitoids from southern São Francisco Craton, NE Brazil, and implications for the evolution of the Transamazonian Orogeny. J. S. Am. Earth Sci., 13: 225-239.

Noce C.M., Zucchetti M., Baltazar O.F., Armstrong R., Dantas E.L., Renger F.E., Lobato L. M. 2005. Age of felsic volcanism and the role of ancient continental crust in the evolution of the Neoarchean Rio das Velhas greenstone belt (Quadrilátero Ferrífero, Brazil): $\mathrm{U}-\mathrm{Pb}$ zircon dating of volcaniclastic graywackes. Precambrian Res., 141: 67-82.

Noce, C.M., Pedrosa-Soares, A.C., Silva, L.C., Armstrong, R., Piuzana, D. 2007. Evolution of polycyclic basement complexes in the Araçuaí Orogen, based on U-Pb SHRIMP data: Implications for Brazil-Africa links in Paleoproterozoic time. Precambrian Res. (in press)

Padilha A.V. 1993. Contexto geológico regional. In: N. Signorelli Programa Levantamentos Geológicos Básicos do Brasil, escala 1:100.000 (Folha SF.24-V-A-II, Afonso Cláudio) Estado do Espírito Santo. Brasília, DNPM/CPRM, p.15-29.

Pedrosa-Soares A.C., Noce C.M., Wiedemann C.M., Pinto C.P 2001. The Araçuaí-West Congo orogen in Brazil: An overview of a confined orogen formed during Gondwanland assembly. Precambrian Res., 110:307-323.

Peres G.G., Alkmim F.F., Jordt-Evangelista H. 2004. The southern Araçuaí belt and the Dom Silvério Group: geologic architecture and tectonic significance. Anais Acad. Bras. Ciênc., 76:771790.

Porada H., 1989. Pan-African rifting and orogenesis in southern to equatorial Africa and Eastern Brazil. Precambrian Res., 44:103-136.

Rogers J.W. \& Santosh M., 2004. Continents and Supercontinents. Oxford University Press, 289 p.

Roque N.C., Grossi-Sad J.H., Noce C.M., Fonseca E. 1993. Geologia da Folha Rio Pardo de Minas, Minas Gerais. Belo Horizonte,
UFMG/COMIG, p.135-207.

Rosa M.L.S., Conceição H., Oberli F., Meir M., Martin H., Macambira M.J.B., Santos E.B., Paim M.M., Leahy A.S., Leal L.R.B. 2000. Geochronology (U-Pb/Pb- $\mathrm{Pb})$ and isotopic signature $(\mathrm{Rb}-\mathrm{Sr} / \mathrm{Sm}-$ $\mathrm{Nd}$ ) of the Paleoproterozoic Guanambi Batholith, southwest Bahia State (NE Brazil). Rev. Bras. Geociênc., 30:62-65.

Rosier G.F. 1957. A Geologia da Serra do Mar, entre os picos de Maria Comprida e do Desengano. Rio de Janeiro, DNPM/GGM, Boletim 166, 58 p.

Seidensticker U. \& Wiedemann C.M., 1992. Geochemistry and origin of lower crustal granulite facies rocks in the Serra do Caparaó region, Espírito Santo/Minas Gerais, Brazil. J. South Am. Earth Sci., 6:289-298.

Silva J. N. 1978. Projeto Mantiqueira-Furnas: relatório final. Belo Horizonte, DNPN/CPRM.

Silva J.M.R., Lima M.I.C., Veronese V.F. et al. 1987. Geologia. In: Projeto RADAMBRASIL: Folha Rio Doce - SE.24. Rio de Janeiro, IBGE, V.34, Cap.1, p. 23-172.

Silva L.C., Armstrong R., Noce C.M, Carneiro M.A., Pimentel M.M., Pedrosa-Soares A.C., Leite C.A., Vieira V.S., Silva M.A., Paes V.J.C., Cardoso-Filho J.M. 2002. Reavaliação da evolução geológica em terrenos pré-cambrianos brasileiros com base em novos dados U-Pb SHRIMP, parte II: Orógeno Araçuaí, Cinturão Mineiro e Cráton São Francisco Meridional. Rev. Bras. Geociênc., 32:513-528.

Silva L.C., Armstrong R., Noce C.M, Carneiro M.A., Pimentel M.M., Pedrosa-Soares A.C., Leite C.A., Vieira V.S., Silva M.A., Paes V.J.C., Cardoso-Filho J.M. 2004. Reply: Reavaliação da evolução geológica em terrenos pré-cambrianos brasileiros com base em novos dados U-Pb SHRIMP, parte II: Orógeno Araçuaí, Cinturão Mineiro e Cráton São Francisco Meridional. Rev. Bras. Geociênc., 34:597-601.

Silva L.C., McNaughton N.J., Armstrong R., Hartmann L.A., Fletcher I.R., 2005. The neoproterozoic Mantiqueira Province and its African connections: a zircon-based $\mathrm{U}-\mathrm{Pb}$ geochronologic subdivision for the Brasiliano/Pan-African systems of orogens Precambrian Res., 136:203-240.

Söllner H.S., Lammerer B., Weber-Diefenbach K. 1991. Die Krustenentwicklung in der Küstenregion nördlich von Rio de Janeiro, Brasilien. Müncher Geologische Hefte, 4:1-100.

Teixeira W. 1985. A evolução geotectônica da porção meridional do Cráton do São Francisco com base em interpretações geocronológicas. Tese de Doutorado, Instituto de Geociências, Universidade de São Paulo, 207p

Teixeira W., Sabaté P., Barbosa J., Noce C. M., Carneiro M. A. 2000. Archean and Paleoproterozoic tectonic evolution of the São Francisco Craton. In: U.G. Cordani, E.J. Milani, A. ThomazFilho, D.A. Campos, D. A. (eds.) Tectonic Evolution of South America. Rio de Janeiro, p. 101-138.

Teixeira W., Ávila, C.A., Cordani, U.G., Martins, V.T.S., Valença, J. 2004. Dados isotópicos $(\mathrm{U} / \mathrm{Pb}, \mathrm{Pb} / \mathrm{Pb}, \mathrm{Sm} / \mathrm{Nd}, \mathrm{Rb} / \mathrm{Sr})$ do plutonismo paleoproterozóico do Cinturão Mineiro, porção meridional do Cráton do São Francisco. In: Simpósio sobre o Cráton do São Francisco, 3, Short Papers, p.174-177.

Trompette R., 1994. Geology of Western Gondwana (2000-500 Ma). Pan-African-Brasiliano aggregation of South America and Africa. A.A. Balkema, 350 p.

Tuller P.M. 2000. Ipanema. Folha SE.24-Y-C-IV, Estado de Minas Gerais, Escala !.100.000. Texto Explicativo-Geologia. Belo Horizonte, CPRM/COMIG, v. 26.

Valença J.G.; Silva M.A.; Schimitt R.S.; Trouw R.A.J.; Noce C.M. 2000. Transamazonian gabbronoritic intrusive rocks from the southernmost São Francisco Craton Brazil). In: International Geological Congress, 31, Abstracts 